\title{
TEMPERATURE MODIFICATION OF MALE SEX PHEROMONE RESPONSE AND FACTORS AFFECTING FEMALE CALLING IN HOLOMELINA IMMACULATA (LEPIDOPTERA: ARCTIIDAE) ${ }^{1}$
}

\author{
R. T. Cardé and W. L. Roelofs \\ Department of Entomology, New York State Agricultural Experiment Station, Geneva
}

\begin{abstract}
Can. Ent. 105: 1505-1512 (1973)

In Holomelina immaculata (Reakirt) periodicity of male attraction to synthetic 2-methylheptadecane, the female-produced sex pheromone, is modified by temperature cues. In the field this response interval occurs from approximately sunset to about $4 \mathrm{~h}$ after sunset on a warm day and night $\left(30^{\circ}\right.$ to $\left.17^{\circ} \mathrm{C}\right)$ and for the $2 \mathrm{~h}$ prior to sunset on a cool day and night $\left(23^{\circ}\right.$ to $\left.16^{\circ} \mathrm{C}\right)$.

In laboratory studies at $24^{\circ} \mathrm{C}$ female $H$. immaculata placed in continual scotophase have an endogenous calling rhythm, but they are apparently inhibited from calling by constant photophase. In 16:8 or 12:12 light-dark cycles at $24^{\circ} \mathrm{C}$ calling occurs from the 2 nd to the 6th hour of scotophase, whereas at $15^{\circ} \mathrm{C}$ calling takes place from the initiation to the 5 th hour of scotophase. The critical cues governing initiation of calling behaviour are lights-off or a temperature decrease cue, and a temperature decrease signal overrides the apparent inhibitory effect of continual photophase.
\end{abstract}

\section{Introduction}

Exclusive mating periodicity rhythms generally have been accepted as primary mechanisms in the reproductive isolation of many closely re. ated species that utilize a common sex attractant communication system. These $\mathrm{m}$ ating cycles have been considered to be endogenous, relatively invariable, and regulated by photoperiod. Recently, field observations of several moth species have revealed that periodicity of male response may be modified by temperature (Cardé 1971; Comeau 1971) and season (Saario et al. 1970; Batiste 1971; Comeau 1971). Similarly, laboratory experiments have shown that periodicity of female calling (protrusion of the pheromone-producing gland) may be modified by temperature (Comeau 1971; Sower et al. 1971; Sanders and Lucuik 1972). This paper describes research with an arctiid moth, Holomelina immaculata (Reakirt), on temperature modifications of its male attraction rhythm, and the influence of lights-on, lights-off and temperature decreases on female calling periodicity. Details on the characterization of the pheromone, 2-methylheptadecane, from $H$. immaculata and related sibling species in the $H$. aurantiaca (Hübner) complex, were presented in an earlier paper (Roelofs and Cardé 1971).

\section{Materials and Methods}

Observations of feral male behaviour were conducted in Dryden, Tompkins County, New York, in 1970 in an abandoned field in about the 10th year of secondary succession. Synthetic 2-methylheptadecane ( $>99 \%$ purity by gas chromatography) was placed on $5 \times 9 \mathrm{~mm}$ rubber septa (Arthur H. Thomas Co.) at amounts of 100 and $1000 \mu \mathrm{g}$ and these dispensers were placed in the bottom centre of white Sectar ${ }^{\circledR}$ I sticky traps $(3 \mathrm{M} \mathrm{Co}$.). Traps were deployed at ground level (separated by $10 \mathrm{~m}$ or more) and were checked at hourly intervals.

Female calling periodicity was determined in the laboratory. Insects were reared individually in $25 \mathrm{cc}$ clear plastic cups (Premium Plastics) on a pinto bean 1Approved by the Director of the New York State Agricultural Experiment Station, Geneva, as Journal
Paper No. 2041. 
medium modified from Shorey and Hale (1965). Temperature was maintained at $24^{\circ} \mathrm{C}$ with a $16 \mathrm{~h}$ photoperiod at $2800 \mathrm{lux}$. For observations of calling behaviour, 0-1 day-old females were confined individually in airtight clear plastic vials $5 \mathrm{~cm}$ in diameter and $8.5 \mathrm{~cm}$ in height. Scotophase viewing was accomplished with a low intensity light filtered with Kodak Wratten filter 29, eliminating light below $6100 \AA$. Females were observed at hourly intervals, during which time the light was directed at the female only long enough to ascertain if she was calling (generally less than $10 \mathrm{sec}$ ).

\section{Results}

\section{Temperature Modification of the Diel Rhythm of Male Attraction Response}

Field observations of periodicity of $H$. immaculata male attraction to 2-methylheptadecane indicate that the initiation and periodicity of attraction can be shifted by ambient temperature. On a warm summer day and night, males were lured to pheromone from approximately sunset for about $4 \mathrm{~h}$ (Fig. 1). On a cool summer day and night, male attraction was initiated $2 \mathrm{~h}$ prior to sunset and most attraction response had terminated by sunset (Fig. 2).

\section{Calling Behaviour of Individual Females within the Calling Period}

The calling behaviour of females includes both the protrusion of the ovipositor and pheromone-producing gland between abdominal segments 8 and 9 and also a characteristic stance (Fig. 3) in which the wings are raised from the normal rooflike resting attitude (Fig. 4). At $24^{\circ} \mathrm{C}$ all calling females exhibit this wing position, but at $15^{\circ} \mathrm{C}$ females hold their wings in various positions intermediate between the calling and resting attitudes at $24^{\circ} \mathrm{C}$. The ovipositor is protruded rhythmically at a rate of 1.21 protrusions per second at $24^{\circ} \mathrm{C}$ and 0.50 protrusion per second at $15^{\circ} \mathrm{C}$. Although continuous observations of calling were not conducted, individual females under $16: 8$ or $12: 12$ light-dark cycles checked at $0.25 \mathrm{~h}$ intervals were found to call continuously within the calling interval. During certain modified light and temperature cycles such as continuous darkness, some females called intermittently.
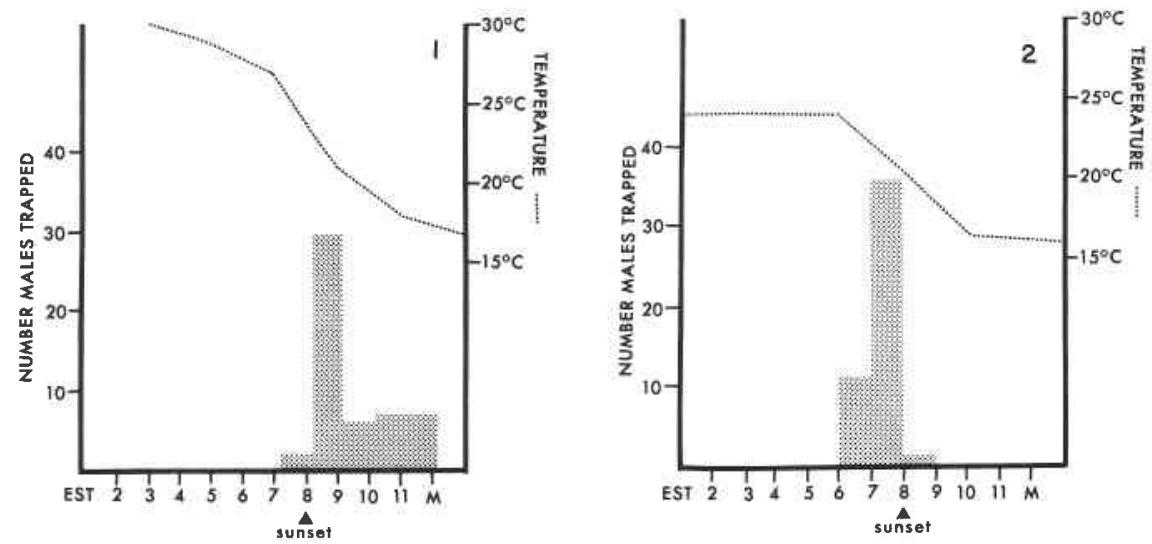

Fig. 1. Diel periodicity of male attraction to 2-methylheptadecàne on 11 June 1970 . Sunrise 0430, sunset 1940 (Eastern Standard Time).

FIG. 2: Diel periodicity of male attraction to 2-methyleheptadecane on 14 June 1970 : 

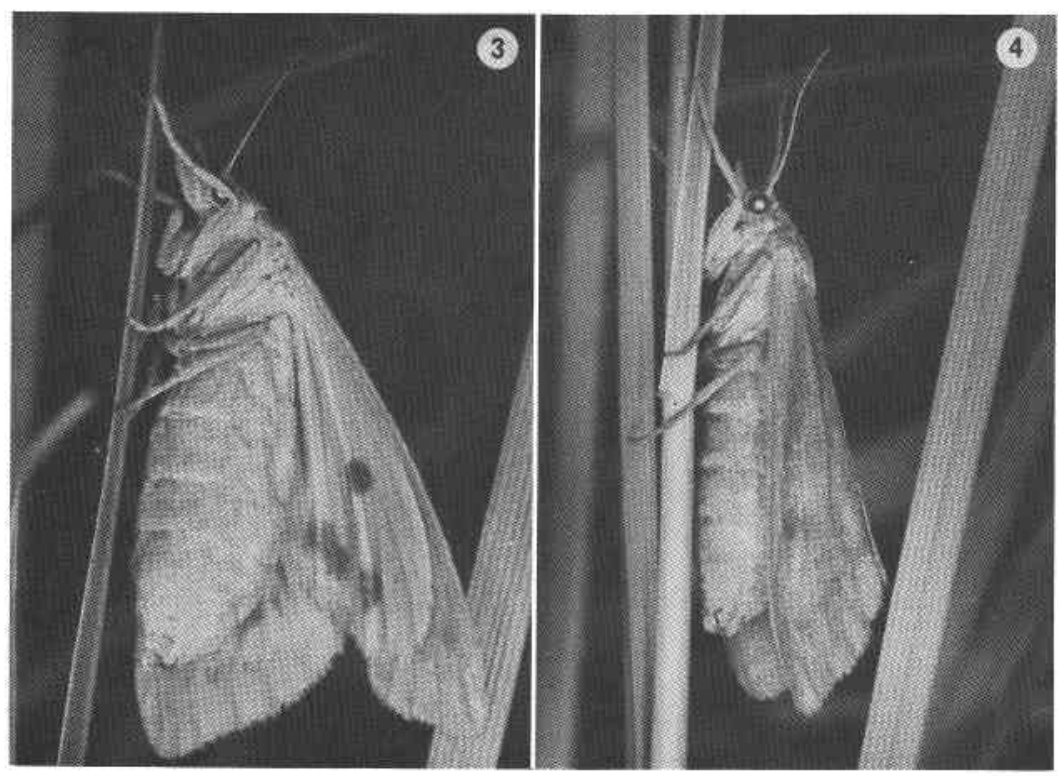

FIGs. 3-4. Calling stance (3) and resting position (4) of female H. immaculata.

In a $16: 8$ photoperiod regime at $24^{\circ} \mathrm{C}$, the following additional species have been noted (Cardé 1971) to possess the same calling stance: aurantiaca, rubicundaria (Hübner), ferruginosa (Walker), nigricans (Reakirt), lamae (Freeman), and an undescribed species from the Black Hills of Wyoming.

\section{Demonstration of an Endogenous Calling Rhythm}

Many laboratory observations have established that under a 16:8 h lightdark cycle at $24^{\circ} \mathrm{C}$ female $H$. immaculata initiate calling between the 2 nd and 4 th hour of scotophase, with more than $50 \%$ of the females calling by the 3 rd hour of scotophase. When females that have cycled through one calling period are maintained in continual darkness at $24^{\circ} \mathrm{C}$, calling occurs at approximately the same $24-\mathrm{h}$ interval (Fig. 5), thus establishing that female calling periodicity has a circadian basis. In contrast, if females that have cycled through one calling period are held in continual light (Fig. 6), none of the females call, indicating that at a constant $24^{\circ} \mathrm{C}$ continual photophase apparently inhibits calling behaviour.

\section{Effect of Lights-On and Lights-Off on the Initiation and Entrainment of Calling}

Females were observed through a normal 16:8 light-dark cycle, followed by a 32-h photophase and an 8-h scotophase. The calling periodicities during both scotophases were essentially identical (Fig. 7), suggesting that the lights-off signal serves to synchronize the calling rhythm. In a separate test females were cycled through a standard 16:8 light-dark regime, a 35-h photophase and observed through $36 \mathrm{~h}$ of scotophase. During this latter scotophase female calling periodicities commenced (from none to more than $50 \%$ ) from the 2 nd to 3 rd hour and again from the 26th to 27 th hour of scotophase, establishing that the lights-off cue entrains the calling rhythm. Under conditions of a normal 8-h scotophase, followed by an 8-h photophase and a 16:8 light-dark cycle (Fig. 8), it is evident that initiation of 

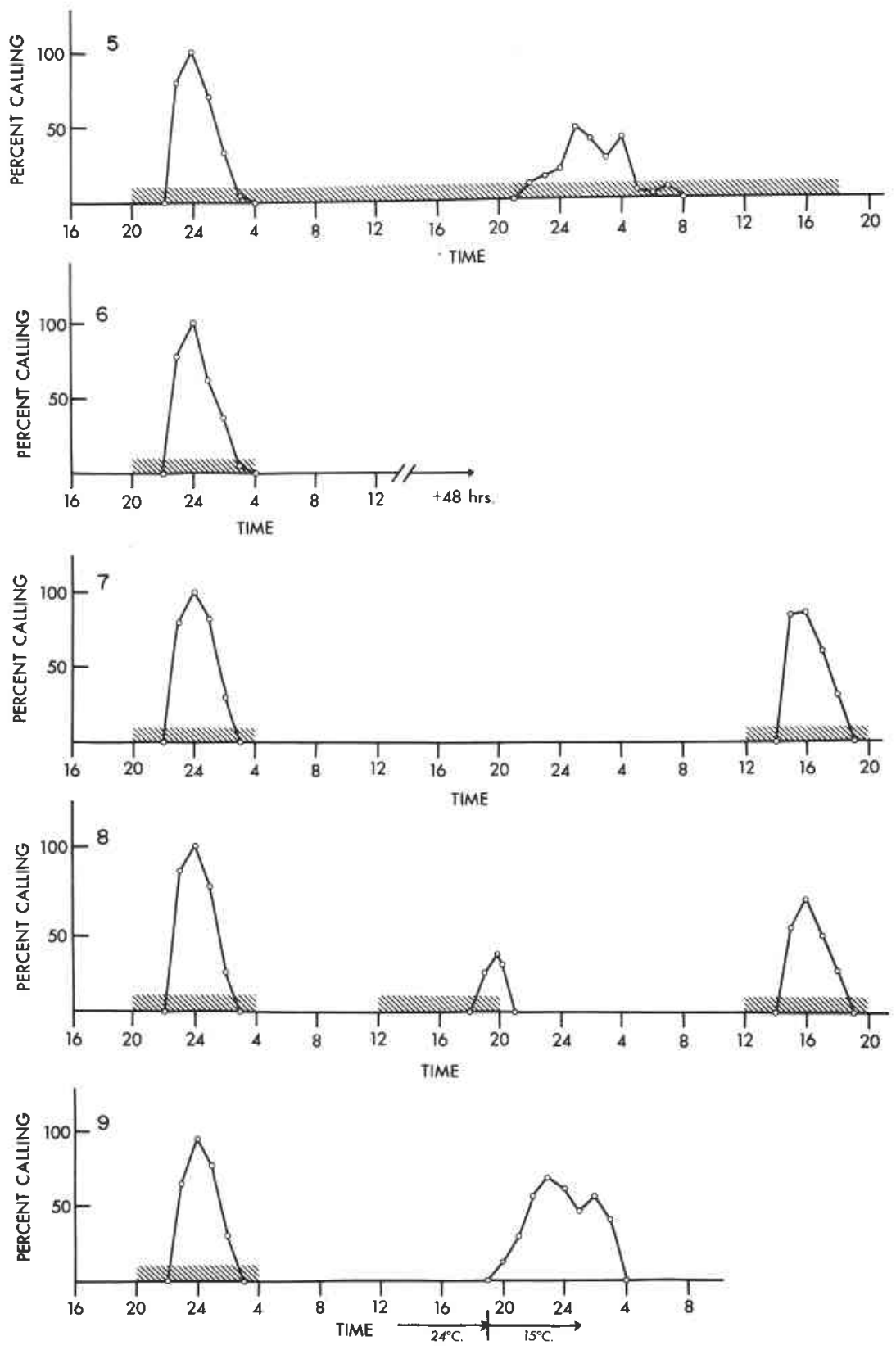
a second calling period within less than $24 \mathrm{~h}$ is limited by an endogenous rhythm. In this experiment some females did call toward the end of the 2nd scotophase, but lights-on apparently terminated calling behaviour. After the $16-\mathrm{h}$ photoperiod, calling periodicity within the 8-h scotophase followed the normal pattern with respect to the lights-on cue.

\section{Effect of a Temperature Decrease on the Initiation of Calling}

In accordance with the observed temperature shift in periodicity of male attraction response, a decrease in ambient temperature could be expected to modify the female calling rhythm. When a standard 8 -h scotophase is followed by continuous light (Fig. 6), no calling occurs in the continuous photophase. If the temperature is decreased rapidly from $24^{\circ} \mathrm{C}$ to $15^{\circ} \mathrm{C} 1 \mathrm{~h}$ before scotophase would normally occur in a 16:8 light-dark regime, in most females calling is initiated within $1 \mathrm{~h}$ and the peak of calling occurs within $2 \mathrm{~h}$ (Fig. 9). In the same way, females held for a long period of photophase such as $32 \mathrm{~h}$ followed by a temperature drop from $24^{\circ} \mathrm{C}$ to $15^{\circ} \mathrm{C}$ also initiate calling within $1 \mathrm{~h}$ with maximal calling occurring within 2 $\mathrm{h}$ of this event (Fig. 10). Such experiments indicate that either a temperature decrease or lights-off can initiate calling behaviour. Further, a temperature decrease overrides the apparent inhibitory effect of continuous photophase on calling behaviour.

\section{Normal Calling Patterns in Relation to 16:8 and 12:12 Light-Dark Cycles and Temperature Changes}

Females conditioned to a 12:12 light-dark cycle were obtained by transferring pre-pupae or pupae less than 1 day old on the $16: 8$ rearing conditions to a 12:12 regime. Eclosion of the females occurred in about 10 days. A comparison (Figs. 11,13) of the females' calling periodicity for two complete cycles of 16:8 vs. $12: 12$ at a $24^{\circ} \mathrm{C}$ constant temperature shows that females exhibit the same periodicity with respect to the lights-off signal, as expected from the earlier experiments. Similarly, when females on 16:8 and 12:12 photoperiod regimes (Figs. 12, 14) are subjected to a rapid temperature decrease $\left(24^{\circ} \mathrm{C}\right.$ to $\left.15^{\circ} \mathrm{C}\right) 1 \mathrm{~h}$ prior to lights-off of the first scotophase cycle, calling periodicity is shifted forward approximately $2-3 \mathrm{~h}$. Essentially the same temperature-modified cycle is maintained in the second scotophase in both the 16:8 and 12:12 cycles.

\section{Discussion}

In the Lepidoptera, investigations of female calling and male pheromone response in general have shown some sort of rhythmic periodicity, with certain exceptions, e.g., virgin females of the phyticid Plodia interpunctella (Hübner) call continuously in a 12:12 photoperiod (Brady and Smithwick 1968). An endogenous

FIG. 5. Calling behaviour of females maintained at $24^{\circ} \mathrm{C}$ in a $16: 8$ light:dark cycle followed by continual scotophase. $N=30$.

Fig. 6. Calling behaviour of females maintained at $24^{\circ} \mathrm{C}$ in a $16: 8$ light:dark cycle followed by continual photophase. $N=20$.

Fig. 7. Calling behaviour of females maintained at $24^{\circ} \mathrm{C}$ in a $16: 8$ light:dark cycle followed by a $32 \mathrm{~h}$ photophase and an $8 \mathrm{~h}$ scotophase. $N=46$.

FIg. 8. Calling behaviour of females maintained at $24^{\circ} \mathrm{C}$ in a $16: 8$ light:dark cycle followed by an 8 h photophase, an $8 \mathrm{~h}$ scotophase and a 16:8 light:dark cycle. $N=47$.

FIG. 9. Calling behaviour of females maintained at $24^{\circ} \mathrm{C}$ in a $16: 8$ light:dark cycle followed by continual photophase and a temperature decrease to $15^{\circ} \mathrm{C} 15 \mathrm{~h}$ after termination of scotophase. $N=34$. 

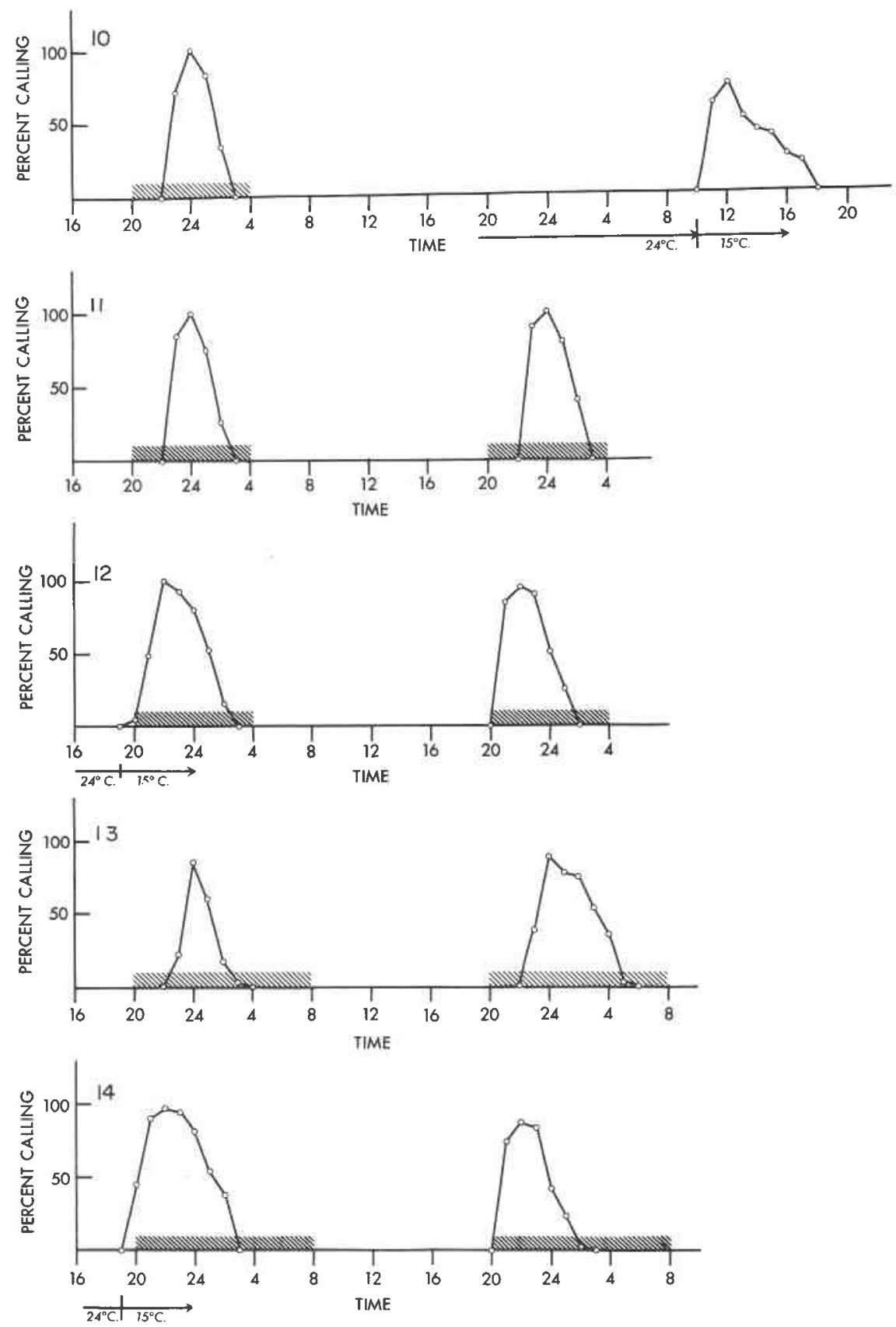
calling rhythm for females placed in continual scotophase has been demonstrated in two moths: Trichoplusia ni (Hübner) by Sower et al. (1970) and Anagasta kühniella (Zeller) by Traynier (1970). It is known in two saturniid species that the corpora cardiaca is a prerequisite for calling behaviour (Riddiford and Williams 1971). Notwithstanding, the environmental factors affecting such rhythms have been elucidated in surprisingly few cases.

In two lepidopterans, lights-on is apparently the critical cue in the timing of female calling periodicity. In $T$. ni, which is known to possess an endogenous circadian rhythm of calling (Sower et al. 1970), calling has been reported to be synchronized to the lights-on signal (Sower et al. 1971). Similarly, Sanders and Lucuik (1972) have indicated that calling behaviour in Choristoneura fumiferana (Clemens) is regulated by the lights-on cue. In contrast the studies reported here indicate that lights-off rather than lights-on is the critical photoperiodic cue governing initiation of calling in female $H$. immaculata.

Periodicity of calling is also known to be modified by temperature in two tortricids, Argyrotaenia velutinana (Walker) as reported by Comeau (1971) and C. fumiferana by Sanders and Lucuik (1972) as well as in the noctuid, T. ni (Sower et al. 1971). In these cases, the periodicity of calling is shifted by various constant temperatures. In $A$. velutinana, females commenced calling at approximately sunset at $20^{\circ} \mathrm{C}, 2 \mathrm{~h}$ prior to sunset at $17^{\circ} \mathrm{C}, 4 \mathrm{~h}$ prior to sunset at $15^{\circ} \mathrm{C}$, and $8 \mathrm{~h}$ prior to sunset at $12^{\circ} \mathrm{C}$. In C. fumiferana the time of $50 \%$ of females calling compared with results at $20^{\circ} \mathrm{C}$ occurred $1 \mathrm{~h}$ earlier at $18^{\circ} \mathrm{C}, 2 \mathrm{hr}$ earlier at $12.5^{\circ} \mathrm{C}$, and $4 \mathrm{~h}$ earlier at $11^{\circ} \mathrm{C}$. In $T$. ni the mean time of calling was observed to occur $4 \mathrm{~h}$ earlier at $18^{\circ} \mathrm{C}$ as compared with $24^{\circ} \mathrm{C}$ (but at the former temperature no more than $6 \%$ of the females were calling at any given time).

$H$. immaculata females also exhibit a similar temperature-induced shift. For instance, at a constant $15^{\circ} \mathrm{C}$, initiation of calling occurred approximately $2 \mathrm{~h}$ earlier than this event takes place at $24^{\circ} \mathrm{C}$ in either a $16: 8$ or a $12: 12$ photoperiod regime. Moreover, these shifts can occur even if the temperature is decreased $1 \mathrm{~h}$ prior to normal lights-off, indicating that long-term temperature conditioning is not necessary for temperature-induced changes in calling rhythm.

Additionally, these studies reveal that although constant light at $24^{\circ} \mathrm{C}$ apparently inhibits all calling behaviour, a decrease to $15^{\circ} \mathrm{C}$ near the time of normal scotophase initiates calling in a manner similar to the lights-off cue. Hence, females of $H$. immaculata possess a dual regulation of their circadian calling rhythm. The endogenous calling rhythm is synchronized and entrained by the lights-off signal. A temperature decrease can modify to some extent the rhythm's initiation within scotophase. A temperature decrease also can serve to induce calling during a photophase, apparently acting in a manner similar to the lights-off cue.

Fig. 10. Calling behaviour of females maintained at $24^{\circ} \mathrm{C}$ in a $16: 8$ light:dark cycle followed by continual photophase and a temperature decrease to $15^{\circ} \mathrm{C} 30 \mathrm{~h}$ after termination of scotophase. $N=20$.

FiG. 11. Calling behaviour of females maintained at $24^{\circ} \mathrm{C}$ in a 16:8 light:dark cycle, $N=25$. FIG. 12. Calling behaviour of females maintained in 16:8 light:dark cycles in which the temperature is decreased from $24^{\circ} \mathrm{C}$ to $15^{\circ} \mathrm{C} 1 \mathrm{~h}$ prior to the first scotophase. $N=25$.

FIG. 13. Calling behaviour of females maintained at $24^{\circ} \mathrm{C}$ in $12: 12$ light:dark cycles. $N=32$.

FIg. 14. Calling behaviour of females maintained in 12:12 light:dark cycles in which the temperature is decreased from $24^{\circ} \mathrm{C}$ to $15^{\circ} \mathrm{C} 1 \mathrm{~h}$ prior to the first scotophase. $N=32$. 
Male attraction response in $H$. immaculata also appears to be affected by temperature, but it is not known if this response rhythm has a circadian basis. Dependent on temperature, periodicity of attraction to 2-methylheptadecane can occur before or after sunset such that, in the 2 days contrasted in Figs. 1 and 2 , the cycles appear to be almost exclusive. As these attraction tests were conducted on clear days with precisely the same light-dark regime, the disparate temperature cycles appear to account for the observed shift in attraction periodicity. Interestingly, on both days male attraction was initiated as the ambient temperature fell below $23^{\circ} \mathrm{C}$ and was terminated at approximately $17^{\circ} \mathrm{C}$.

Comeau (1971) also reported temperature-related shifts in attraction response in a number of tortricids. In $A$. velutinana, male attraction periodicity is known to differ between early spring and summer flights, and such differences may involve both photoperiod and temperature cues. Comparisons of the daily average temperature at which the males were attracted with the average hour of attraction show a high degree of correlation within spring and summer flight periods (each of which possesses essentially the same photoperiod). Attraction to live females or synthetic pheromone occurred in mid-afternoon at cool temperatures (such as less than $15^{\circ} \mathrm{C}$ ) and after sunset at temperatures above $20^{\circ} \mathrm{C}$.

\section{Acknowledgments}

We thank F. Wadhams for maintaining the $H$. immaculata culture and T. Baker for assistance in observations. This research was supported in part by the Rockefeller Foundation.

\section{References}

Batiste, W. C. 1971. A timing sex-pheromone trap with special reference to codling moth collections. J. econ. Ent. 63: 915-918.

Brady, U. E. and E. B. Smithwick. 1968. Production and release of sex attractant by the female Indian-meal moth, Plodia interpunctella. Ann. ent. Soc. Am. 61: 1260-1265.

Cardé, R. T. 1971 (unpub.). Aspects of reproductive isolation in the Holomelina aurantiaca complex (Lepidoptera: Arctiidae). Ph.D. Thesis, Cornell University.

Comeau, A. 1971 (unpub.). Physiology of sex pheromone attraction in Tortricidae and other Lepidoptera (Heterocera). Ph.D. Thesis, Cornell University.

Riddiford, L. M. and C. M. Williams. 1971. Role of the corpora cardiaca in the behavior of saturniid moths. I. Release of the sex pheromone. Biol. Bull. mar. biol. Lab., Woods Hole 140: 1-7.

Roelofs, W. and R. Cardé. 1971. Hydrocarbon sex pheromone in tiger moths (Arctiidae). Science 171: 684-686.

Saario, C. A., H. H. Shorey, and L. K. Gaston. 1970. Sex pheromones of noctuid moths. XIX. Effect of environmental and seasonal factors on captures of males of Trichoplusia $n i$ in pheromone-baited traps. Ann. ent. Soc. Am. 63: 667-672.

Sanders, C. J. and G. S. Lucuik. 1972. Factors affecting calling by female eastern spruce budworm, Choristoneura fumiferana (Lepidoptera: Tortricidae). Can. Ent. 104: 1751-1762.

Shorey, H. H. and R. L. Hale. 1965. Mass rearing of the larvae of nine noctuid species on a simple artificial medium. J. econ. Ent. 58: 522-524.

Sower, L. L., H. H. Shorey, and L. K. Gaston. 1970. Sex pheromones of noctuid moths. XXI. Light: dark cycle regulation and light inhibition of sex pheromone release by females of Trichoplusia ni. Ann. ent. Soc. Am. 63: 1090-1092.

1971. Sex pheromones of noctuid moths. XXV. Effects of temperature and photoperiod on circadian rhythms of sex pheromone release by females of Trichoplusia ni. Ann. ent. Soc. Am. 64: 488-492.

Traynier, R. M. M. 1970. Sexual behaviour of the Mediterranean flour moth, Anagasta kühniella: Some influences of age, photoperiod, and light intensity. Can. Ent. 102: 534-540.

(Received 4 July 1973) 